\title{
Oxygen-dependent erythropoietin production by the isolated perfused rat kidney
}

\author{
H. Scholz, H.J. Schurek, K.-U. Eckardt, A. Kurtz, and C. Bauer \\ Physiologisches Institut der Universität, Winterthurer Strasse 190, CH-8057 Zürich, Switzerland
}

Received November 17, 1989/Received after revison November 23/Accepted December 4, 1990

\begin{abstract}
In this study we have investigated the role of oxygen delivery and of classic second messengers on erythropoietin production by the isolated perfused rat kidney. We found that the rat kidney was capable of de novo synthesis of erythropoietin. The erythropoietin production rate was inversely related to the oxygen pressure in the perfusate and increased from 0.17 to $1.85 \mathrm{U}$ erythropoietin $\mathrm{h}^{-1} \mathrm{~g}_{\text {kidney }}{ }^{-1}$ when arterial $P_{2}$ was lowered from $500 \mathrm{mmHg}$ to $30 \mathrm{mmHg}$. Addition of forskolin $(10 \mu \mathrm{M})$ and 8-bromo-cGMP $(100 \mu \mathrm{M})$ to the perfusate elicited significant effects on the renal vascular resistance, but had no significant effect on erythropoietin production. Hypoxia-induced erythropoietin formation, however, was blocked by calmidazolium $(1 \mu \mathrm{M})$ and $\mathrm{W}-7$ $(10 \mu \mathrm{M})$, two structurally different putative calmodulin antagonists. Calmidazolium and W-7 had no effect on other functional parameters of the isolated perfused rat kidney such as flow rate, glomerular filtration rate or sodium reabsorption. Our findings suggest that the oxygensensing mechanism that controls renal erythropoietin production is primarily located in the kidney itself. A calcium/calmodulin-dependent cellular reaction could be involved in the signal transduction process.
\end{abstract}

Key words: Isolated perfused kidney - Radioimmunoassay - Hypoxia - Renal oxygen sensing cAMP - cGMP - Calmodulin

\section{Introduction}

It is accepted that the kidneys are the main site of erythropoietin (EPO) synthesis in the organism $[12,14]$. Within the kidneys EPO is most likely produced by cortical peritubular cells, depending on the oxygen supply to the kidneys $[15,18]$. Recently, evidence was provided that EPO production is regulated at least in part by the rate

Offprint requests to: $\mathrm{H}$. Scholz of gene transcription $[2,3,25,26]$. However, it is still subject to discussion whether the sensing of oxygen supply and its transduction into adequate EPO synthesis are performed extrarenally or in the kidney itself [1]. A strong argument for an oxygen-sensing function of the kidney would be the demonstration that the isolated kidney is capable of producing EPO in an oxygen-dependent manner, as is known to occur in the intact organism. In fact, it has been reported that isolated perfused kidneys release more EPO when the oxygen supply is lowered [7, 9, 16, 28]. In those studies the amount of EPO released from isolated kidneys was determined indirectly either by measuring EPO dependent ${ }^{59} \mathrm{Fe}$ incorporation into red blood cells $[7,9,28]$ or by determination of the proliferative activity of the erythron [16]. Moreover, those experiments were partly performed in kidneys isolated from hypoxic animals, a fact that makes it difficult to distinguish whether EPO formation had been really induced or had merely been modulated during ex vivo perfusion [7]. A major argument against an essential "oxygen sensing" by the kidney is that a severe reduction of renal oxygen supply by selective reduction of renal perfusion only causes a slight increase of EPO formation while the same decrease of oxygen supply by a reduction of the systemic oxygen transport capacity leads to an exponentially increasing EPO production [20].

In view of these conflicting findings it seemed reasonable to examine whether EPO production can be reproducibly induced by oxygen depletion in isolated perfused kidneys, taken from normoxic animals. To this end isolated kidneys were perfused at constant pressure in a recirculatory system containing red cells. To improve the functional conservation of the preparation the perfusate was continuously dialysed during the experiments. The amount of EPO released into the perfusion medium was determined by using a sensitive and specific radioimmunoassay [5].

If EPO formation could really be induced in isolated perfused kidneys taken from normoxic animals by oxygen depletion, then this model could be used to investigate the principles of the signal transduction that link EPO 
production to oxygen delivery. Even though the oxygensensing mechanism underlying EPO formation remains rather elusive at the moment, it is conceivable that EPO synthesis might be controlled by intracellular release of second-messenger molecules. Therefore, as a first approach, we have examined the effects of the classic second messengers such as cyclic AMP, cyclic GMP and calcium/calmodulin on EPO production by the isolated perfused rat kidney.

\section{Materials and methods}

Male SIV strain rats (250-350 g body weight), which had free access to commercial chow and tap water before the experiments, were used throughout. According to the technique described by Schurek and Alt [24], kidney perfusion was performed as follows: rats were anaesthetized by intraperitoneal injection of $150 \mathrm{mg} / \mathrm{kg}$ 5-ethyl-5 (1'-methylpropyl)-2-thiobarbituric acid (Inactin, Byk Gulden, Konstanz, FRG). During preparation, respiration was maintained using a Harvard respirator (75 strokes/min, stroke volume $2 \mathrm{ml}, 25 \% \mathrm{O}_{2}$ ). Following abdominal midline incision, the right ureter was cannulated with a polypropylene tube (PP-10) connected to a larger polyethylene catheter (PE-50). After intravenous heparin injection ( $2 \mathrm{U} / \mathrm{g}$ body weight Liquemin, Roche, Basel, Switzerland) via a catheter in the jugular vein, the kidney was placed in a metal chamber fixed at a micropuncture table. The arterial branches of the abdominal aorta were ligated and a double-barreled cannula was inserted into the aorta and placed at the origin of the renal artery. To avoid renal ischaemia, perfusion was started in situ with an initial flow rate of $8 \mathrm{ml} / \mathrm{min}$. The kidney was isolated from the animal and, about $10 \mathrm{~min}$ later, perfusion at constant pressure was established. The effective perfusion pressure was monitored through the inner part of the cannula (Statham transducer P10EZ) and held constant at $100 \mathrm{mmHg}$ by means of a feedback-regulated peristaltic pump. The perfusion medium consisted of a Krebs-Henseleit physiological saline containing all physiological amino acids in concentrations between $0.2 \mathrm{mM}$ and $2.0 \mathrm{mM}, 8.7 \mathrm{mM}$ glucose, $0.3 \mathrm{mM}$ pyruvate, $2.0 \mathrm{mM} L$-lactate, $1.0 \mathrm{mM}$ 2-oxoglutarate, $1.0 \mathrm{mM}$ L-malate and $6.0 \mathrm{mM}$ urea. Thyroid hormone $(150 \mathrm{ng} / 100 \mathrm{ml}),\left[\mathrm{Lys}^{8}\right]$ vasopressin $(1 \mathrm{mU} / 100 \mathrm{ml})$ and polyfructosan $(1 \mathrm{~g} / 1)$ were also added. Ampicillin and flucloxacillin $(3 \mathrm{mg} / 100 \mathrm{ml}$ each) were used as antibiotics. Moreover, the perfusate contained $2 \mathrm{~g} / 100 \mathrm{ml}$ bovine serum albumin and a $9 \%-11 \%$ fraction of three times freshly washed human erythrocytes. An in-line filter $(8 \mu \mathrm{m}$ pore size) was used during the preperfusion period, before erythrocytes were added, to remove small particles from the circulation. The perfusate, which was thermostated to $37^{\circ} \mathrm{C}$, was taken from a reservoir $(200-220 \mathrm{ml})$. The experiments were performed in a recirculatory perfusion system. To this end the renal vein was catheterized with a metal cannula and the venous effluent was drained back into the reservoir. To improve the functional conservation of the preparation the perfusion medium was continuously dialysed against a 20 -fold volume of proteinfree Krebs-Henseleit solution. Oxygen delivery to the kidney was adjusted by equilibrating the dialysate with gas mixtures containing various amounts of oxygen. Oxygen partial pressure was measured in the venous outflow or in an arterial bypass using an in-line Clark type $\mathrm{O}_{2}$-electrode (Eschweiler, Kiel, FRG). Before and after each experiment, the $\mathrm{O}_{2}$ electrode was calibrated with nitrogen and $100 \%$ oxygen, respectively. The perfusion flow rate was obtained from the pump revolutions. Perfusion pressure, flow rate, and arterial and venous $\mathrm{PO}_{2}$ in the perfusate were continuously monitored by a potentiometric recorder (Kipp \& Zonen, Delft, Netherlands). EPO was assayed in aliquots drawn from the perfusion medium at 30 -min intervals. To obtain steadystate conditions the tested drugs, dissolved in freshly prepared perfusion medium, were continuously infused into the arterial limb of the circulation directly in front of the kidney. Addition of the compounds was normally started about $30 \mathrm{~min}$ after the onset of perfusion and maintained for a 1 -h period. A flow-proportional infusion rate of $2 \%$ of the perfusion flow was adjusted by using a peristaltic pump (2132 Microperpex, LKB, Bomma, Sweden).

\section{Analytical methods}

Determination of EPO. Before assay for EPO, perfusate samples were concentrated 5 to 7-fold by ultrafiltration through low-absorption YM membranes with a $30-\mathrm{kDa}$ molecular mass cutoff and a measured recovery for ${ }^{125}$ I-EPO of approximately $90 \%$ (Centricon microconcentrators, Amicon, USA). EPO was measured by radioimmunoassay as described [5] using a rabbit antiserum raised against recombinant human EPO and iodinated recombinant EPO (Amersham Lab., England) as tracer. A serum pool obtained from hypoxic rats was used as standard after previous determination of the EPO content by in vivo bioassay [5].

Determination of sodium and potassium. Sodium and potassium were analysed by flame photometry (Instrumentation Laboratory 943).

Determination of glomerular filtration rate. The glomerular filtration rate was obtained from polyfructosan (Laevosan, Linz, Austria) clearance. Polyfructosan was measured after acid hydrolysis by a phosphohexose isomerase reaction [23].

Calculation of oxygen consumption. Oxygen consumption of the kidneys was calculated from the arterio-venous $\mathrm{PO}_{2}$ difference of physically dissolved and haemoglobin-bound oxygen and the perfusion flow rate. Concentrations of dissolved oxygen were calculated from the arterial and venous $\mathrm{PO}_{2}$ values using the absorption coefficient for oxygen $\left(\alpha \mathrm{O}_{2}=0.0227\right)$ in physiological saline at $37^{\circ} \mathrm{C}$. For determination of haemoglobin-bound oxygen an oxygen-binding curve was made for every perfusate by tonometry (Instrumentation Laboratory 237). Haemoglobin concentrations were measured spectrophotometrically (CO-Oximeter, Instrumentation Laboratory 282). Arterio-venous differences of haemoglobin-bound oxygen were then calculated from the oxygen-binding curves, the haemoglobin concentrations and the respective arterial and venous $\mathrm{PO}_{2}$ values.

Materials. Pyruvate and the test kit for polyfructosan determination were obtained from Boehringer, Mannheim, FRG. Ampicillin and flucloxacillin were from Beecham, Bern, Switzerland. Glutamate, urea, and 2-oxoglutarate were provided by Merck, Darmstadt, FRG. L-Malic acid and L-lactate as sodium salts were obtained from Serva, Heidelberg, FRG. Bovine serum albumin, cyclic 8-bromo-GMP and $N$ (6-aminohexyl)-5-chloro-1-naphthalenesulphonamide (W-7) were from Sigma International. Thyroid hormone was supplied by Henning, Berlin, and L-amino acids by Braun/Melsungen, FRG (Aminoplasmal paed. free of carbon hydrates). Polyfructosan was purchased from Laevosan, Linz, Austria, and $\left[\mathrm{Lys}^{8}\right]$ vasopressin from Sandoz, Basel, Switzerland. Forskolin was obtained from Calbiochem, Luzern, Switzerland, and calmidazolium from Janssen, Olen, Belgium.

Statistics. Student's $t$-test was used for comparison of groups and anal$y$ sis of variance to determine levels of significance. $P<0.05$ was considered significant.

\section{Results}

EPO release from kidneys perfused at $\mathrm{PO}_{2}$ values of $500 \mathrm{mmHg}$ and $120 \mathrm{mmHg}$ is shown in Fig. $1 \mathrm{a}$. At $500 \mathrm{mmHg}$ the amount of EPO released by the kidneys rose almost linearly during the first $3 \mathrm{~h}$ of perfusion and reached a constant level further on. For this condition the EPO production rate was calculated to be $0.17 \pm 0.02 \mathrm{U}$ $\mathrm{h}^{-1} \mathrm{~g}$ kidney $^{-1}$ (mean $\pm \mathrm{SEM}, n=5$ ). When perfused at an oxygen pressure of $120 \mathrm{mmHg}$, EPO release significantly increased 60-90 min after the onset of perfusion $(P<0.05)$. After $3.5 \mathrm{~h}$ of perfusion the amount of EPO present in the perfusate remained constant. For the phase of linear increase (between $90 \mathrm{~min}$ and $150 \mathrm{~min}$ ) the EPO production rate was calculated to be $1.2 \pm 0.1 \mathrm{U} \mathrm{h}^{-1} \mathrm{~g}$ 

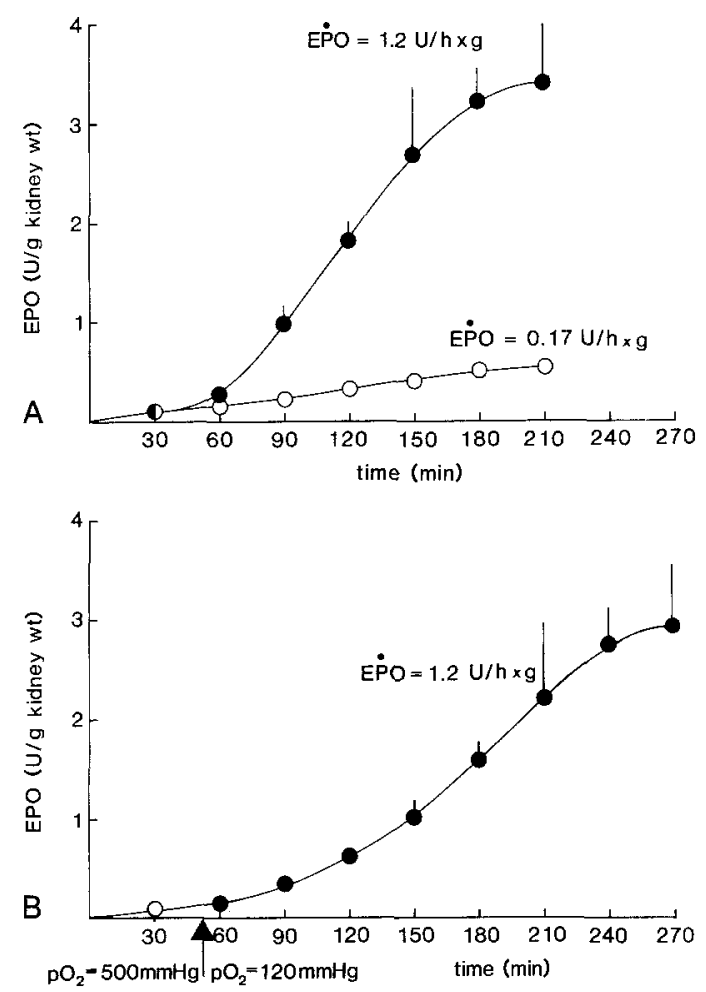

Fig. 1. Time-dependent erythropoietin $(E P O)$ production by isolated rat kidneys (A) perfused at arterial $P_{2}$ values of $500 \mathrm{mmHg}(O)$ and $120 \mathrm{mmHg}(\bullet)$ and (B) perfused first at $500 \mathrm{mmHg}(\mathrm{O})$ and subsequently at $120 \mathrm{mmHg}(\bullet)$. A Increase of erythropoietin release from kidneys perfused at $\mathrm{PO}_{2}$ values of $120 \mathrm{mmHg}$ was statistically significant from $60 \mathrm{~min}$ after the onset of perfusion $(P<0.05)$. EPO formation rates were calculated for the phase of linear increase. Values are means $\pm \mathrm{SEM}, n=5$. B Arterial $P \mathrm{O}_{2}$ was lowered to $120 \mathrm{mmHg} 50 \mathrm{~min}$ after the onset of perfusion (arrow). Note the time lag of $60-90 \mathrm{~min}$ between decrease of oxygen supply and significant increase of EPO release $(P<0.05)$. EPO formation rate (mean $\pm \mathrm{SEM}, n=5$ ) was calculated for the phase of linear increase

kidney $^{-1}$ (mean \pm SEM, $n=5$ ). To test the possibility that the low EPO formation rate of $0.17 \pm 0.02 \mathrm{U} \mathrm{h}^{-1} \mathrm{~g}$ kidney $^{-1}$ at high oxygen pressure might not result from oxygen-dependent regulation of EPO synthesis, but rather from a toxic effect of the high oxygen pressure on the mechanisms controlling EPO formation, kidney perfusion was started at an arterial $\mathrm{PO}_{2}$ of $500 \mathrm{mmHg}$, which was lowered to $120 \mathrm{mmHg} 50 \mathrm{~min}$ after the onset of perfusion (Fig. 1 b). Again, reduction of oxygen pressure was followed by a significantly $(P<0.05)$ increased EPO formation rate of $1.2 \mathrm{U} \mathrm{h}^{-1} \mathrm{~g}^{\text {kidney }}{ }^{-1}$ with a delay of 60-90 min. In further experiments $P_{2}$ was lowered from $500 \mathrm{mmHg}$ to $300 \mathrm{mmHg}$ and from $500 \mathrm{mmHg}$ to $30 \mathrm{mmHg} 50 \mathrm{~min}$ after the onset of perfusion. As in the experiments shown in Fig. 1 b, EPO release increased $60-90 \mathrm{~min}$ after reduction of the renal oxygen supply. The relationship of EPO production rates to the $\mathrm{PO}_{2}$ values in the perfusate is shown in Fig. 2. Apparently, EPO production rates and $\mathrm{PO}_{2}$ values were negatively correlated in an almost linear fashion. The effects of the oxygen tension in the perfusate on flow rate, glomerular filtration rate, sodium reabsorption and oxygen consumption of the isolated perfused rat kidney are summa-
Table 1. Functional parameters of isolated perfused rat kidneys ${ }^{\text {a }}$

\begin{tabular}{|c|c|c|c|c|}
\hline \multirow[t]{2}{*}{ Parameter } & \multirow{2}{*}{$\begin{array}{l}\mathrm{PO}_{2} \\
(\mathrm{mmHg})\end{array}$} & \multicolumn{3}{|c|}{ Value after } \\
\hline & & $30 \mathrm{~min}$ & $90 \mathrm{~min}$ & $150 \mathrm{~min}$ \\
\hline $\begin{array}{l}\text { Perfusion flow rate } \\
\left(\mathrm{ml} \mathrm{min}{ }^{-1} \mathrm{~g}^{-1}\right)\end{array}$ & $\begin{array}{l}500 \\
120\end{array}$ & $\begin{array}{l}11 \pm 2 \\
12 \pm 1\end{array}$ & $\begin{array}{l}12 \pm 2 \\
14 \pm 2\end{array}$ & $\begin{array}{l}11 \pm 2 \\
15 \pm 2\end{array}$ \\
\hline GFR $\left(\mathrm{ml} \mathrm{min}{ }^{-1} \mathrm{~g}^{-1}\right)$ & $\begin{array}{l}500 \\
120\end{array}$ & $\begin{array}{l}1.3 \pm 0.1 \\
1.1 \pm 0.1\end{array}$ & $\begin{array}{l}1.2 \pm 0.1 \\
1.0 \pm 0.1\end{array}$ & $\begin{array}{l}1.1 \pm 0.1 \\
0.8 \pm 0.1\end{array}$ \\
\hline $\begin{array}{l}\text { Na reabsorption } \\
(\% \text { of tubular load) }\end{array}$ & $\begin{array}{l}500 \\
120\end{array}$ & $\begin{array}{l}87 \pm 2 \\
82 \pm 4\end{array}$ & $\begin{array}{l}73 \pm 6 \\
65 \pm 6\end{array}$ & $\begin{array}{l}62 \pm 4 \\
56 \pm 6\end{array}$ \\
\hline $\begin{array}{l}\mathrm{QO}_{2} \\
\left(\mu \mathrm{mol} \min ^{-1} \mathrm{~g}^{-1}\right)\end{array}$ & $\begin{array}{l}500 \\
120\end{array}$ & $\begin{array}{l}6.4 \pm 1.2 \\
6.2 \pm 0.9\end{array}$ & $\begin{array}{l}6.5 \pm 1.0 \\
4.8 \pm 0.9\end{array}$ & $\begin{array}{l}5.0 \pm 1.4 \\
3.9 \pm 0.6\end{array}$ \\
\hline
\end{tabular}

${ }^{\text {a }}$ Functional parameters of kidneys perfused at arterial $\mathrm{PO}_{2}$ values of $500 \mathrm{mmHg}$ and $120 \mathrm{mmHg}$, respectively. Values are expressed as means $\pm \mathrm{SEM}, n=5$; GFR, glomerular filtration rate; $Q \mathrm{O}_{2}$, renal oxygen consumption

rized in Table 1. None of these parameters was significantly different between oxygen pressures of $500 \mathrm{mmHg}$ and $120 \mathrm{mmHg}$. It should be noted that the filtration fractions were relatively low $(10.4 \pm 0.9 \%, n=5)$ because of the high perfusate flow rates observed under our experimental conditions.

In a second set of experiments we tested whether the increase of EPO production by the isolated perfused rat kidney upon lowering the oxygen pressure could be mimicked by classic second-messenger molecules. We used forskolin $(10 \mu \mathrm{M})$ and cyclic 8 -bromo-GMP $(100 \mu \mathrm{M})$ to increase cellular levels of cAMP and cGMP, respectively. Calmidazolium $(1 \mu \mathrm{M})$ was taken to inhibit calmodulin activity [10]. All tested drugs were continuously and flowproportionally infused into the arterial limb of the circulation for a 45 -min period starting $30 \mathrm{~min}$ after the onset of perfusion. As shown in Fig. 3, forskolin $(10 \mu \mathrm{M})$ and 8-bromo-cGMP $(100 \mu \mathrm{M})$ caused a slight but statistically not significant $(P>0.05)$ decrease of EPO formation rates to $0.08 \pm 0.02$ and $0.07 \pm 0.02 \mathrm{U} \mathrm{h}^{-1} \mathrm{~g}^{-1}$ respectively, when perfusion was performed at a $P_{2}$ of $500 \mathrm{mmHg}$ ( $n=3$ for each condition). At the same time forskolin

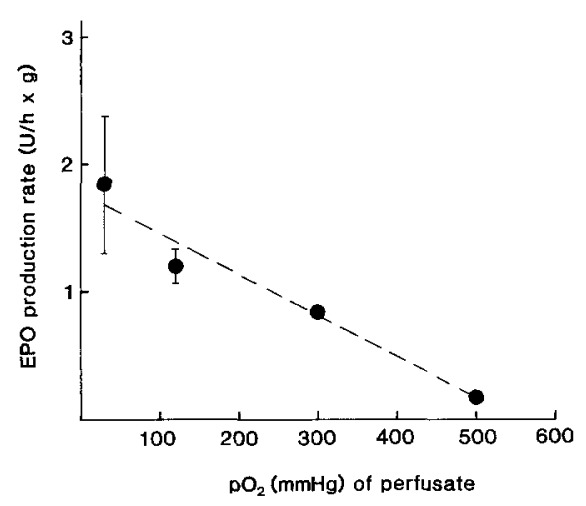

Fig. 2. Relationship between erythropoietin ( $E P O)$ production rate in the isolated perfused rat kidney and oxygen pressure in the perfusate. EPO formation and arterial $\mathrm{PO}_{2}$ values are inversely correlated in an almost linear fashion (regression curve, $\mathrm{P}<0.001$ ). Values are means \pm SEM, $n=5$ 

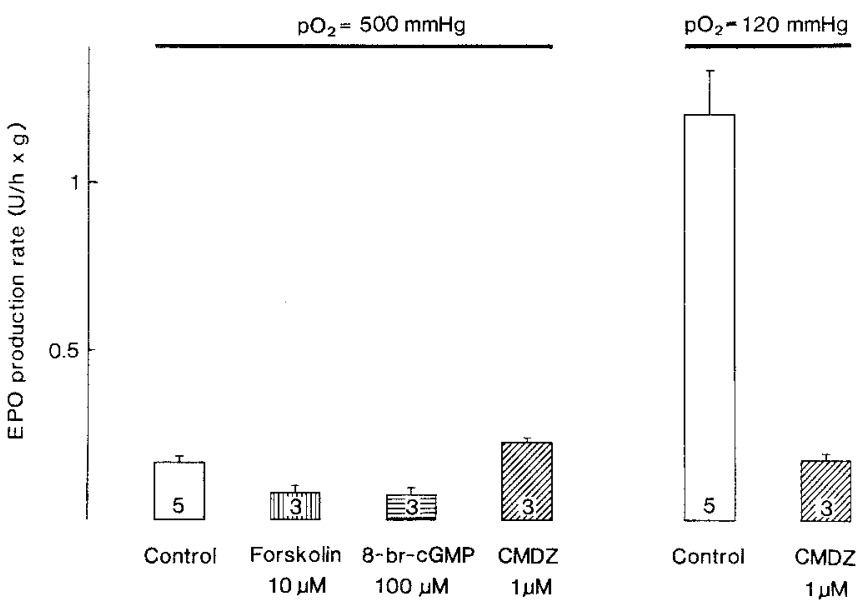

Fig. 3. Erythropoietin ( $E P O$ ) production rates in the isolated perfused rat kidney obtained upon addition of forskolin $(10 \mu \mathrm{M})$, 8-bromocGMP $(100 \mu \mathrm{M})$, and calmidazolium $(1 \mu \mathrm{M})$, respectively. The tested drugs were continuously infused into the arterial limb of the perfusion circuit for a $1-\mathrm{h}$ period. Infusion was normally started $30 \mathrm{~min}$ after the onset of perfusion. Calmidazolium $(1 \mu \mathrm{M})$ blunted the increase of EPO formation upon lowering arterial $P_{2}$ from $500 \mathrm{mmHg}$ to $120 \mathrm{mmHg}$ $(P<0.01)$. Values are means \pm SEM; the number of experiments is indicated at the bottom of each bar

and 8-bromo-cGMP decreased renal vascular resistance (Table 2). Moreover, the drop of oxygen consumption that appeared during the course of the experiments (Table 1) was less pronounced in presence of forskolin, 8-bromo-cGMP and calmidazolium. While calmidazolium had no significant effect on EPO release at an arterial $\mathrm{PO}_{2}$ of $500 \mathrm{mmHg}$ it blunted the increase of EPO pro-

Table 2. Effect of forskolin, 8-bromo-cGMP, and calmidazolium on isolated perfused rat kidneys ${ }^{\mathrm{a}}$

\begin{tabular}{|c|c|c|c|}
\hline \multirow[t]{2}{*}{ Parameter } & \multicolumn{3}{|c|}{ Value after } \\
\hline & $30 \mathrm{~min}$ & $90 \mathrm{~min}$ & $150 \mathrm{~min}$ \\
\hline \multicolumn{4}{|c|}{ Perfusion flow rate $\left(\mathrm{ml} \mathrm{min} \operatorname{mon}^{-1} \mathrm{~g}^{-1}\right)$} \\
\hline Forskolin $(10 \mu \mathrm{M})$ & $13 \pm 1$ & $16 \pm 2 *$ & $13 \pm 2$ \\
\hline 8-Bromo-cGMP $(100 \mu \mathrm{M})$ & $15 \pm 1$ & $22 \pm 1 *$ & $22 \pm 1 *$ \\
\hline Calmidazolium $(1 \mu \mathrm{M})$ & $13 \pm 2$ & $12 \pm 1$ & $11 \pm 1$ \\
\hline \multicolumn{4}{|l|}{ GFR $\left(\mathrm{ml} \mathrm{min}-1 \mathrm{~g}^{-1}\right)$} \\
\hline Forskolin $(10 \mu \mathrm{M})$ & $1.3 \pm 0.1$ & $1.0 \pm 0.1$ & $0.9 \pm 0.1$ \\
\hline 8-Bromo-cGMP $(100 \mu \mathrm{M})$ & $1.5 \pm 0.1$ & $1.3 \pm 0.1$ & $1.0 \pm 0.1$ \\
\hline Calmidazolium $(1 \mu \mathrm{M})$ & $1.1 \pm 0.2$ & $1.2 \pm 0.1$ & $1.4 \pm 0.1$ \\
\hline \multicolumn{4}{|c|}{$\mathrm{Na}$ reabsorption ( $\%$ of tubular load) } \\
\hline Forskolin $(10 \mu \mathrm{M})$ & $73 \pm 1$ & $76 \pm 3$ & \pm 1 \\
\hline 8-Bromo-cGMP $(100 \mu \mathrm{M})$ & $86 \pm 3$ & $77 \pm 1$ & \pm 6 \\
\hline Calmidazolium $(1 \mu \mathrm{M})$ & $90 \pm 2$ & $77 \pm 7$ & \pm 12 \\
\hline \multicolumn{4}{|l|}{$Q \mathrm{O}_{2}\left(\mu \mathrm{mol} \mathrm{min} \operatorname{mog}^{-1} \mathrm{~g}^{-1}\right)$} \\
\hline Forskolin $(10 \mu \mathrm{M})$ & $6.5 \pm 0.1$ & $6.6 \pm 0.1$ & $6.1 \pm 0.1$ \\
\hline 8-Bromo-cGMP $(100 \mu \mathrm{M})$ & $6.8 \pm 0.3$ & $6.2 \pm 0.6$ & $5.7 \pm 0.2$ \\
\hline Calmidazolium $(1 \mu \mathrm{M})$ & $7.2 \pm 0.3$ & $6.7 \pm 0.1$ & $6.1 \pm 0.3$ \\
\hline
\end{tabular}

${ }^{a}$ Kidneys were perfused at $P \mathrm{O}_{2}$ values of $500 \mathrm{mmHg}$. The tested drugs were continuously infused into the arterial limb of the circulation for a 45 -min period starting $30 \mathrm{~min}$ after the onset of perfusion. Values are means $\pm \mathrm{SEM}, n=3$ for each condition

* Significantly different from control $(P<0.05)$
Table 3. Effect of calmidazolium on functional parameters of isolated rat kidneys perfused at $P \mathrm{O}_{2}$ values of $120 \mathrm{mmHg}$

\begin{tabular}{|c|c|c|c|}
\hline \multirow[t]{2}{*}{ Parameter } & \multicolumn{3}{|c|}{ Value after } \\
\hline & $30 \mathrm{~min}$ & $90 \mathrm{~min}$ & $150 \mathrm{~min}$ \\
\hline \multicolumn{4}{|c|}{ Perfusion flow rate $\left(\mathrm{ml} \mathrm{min} \operatorname{mon}^{-1} \mathrm{~g}^{-1}\right)$} \\
\hline Calmidazolium & $12 \pm 1$ & $12 \pm 1$ & $12 \pm 1$ \\
\hline Control & $10 \pm 2$ & $11 \pm 2$ & $13 \pm 3$ \\
\hline \multicolumn{4}{|c|}{ GFR $\left(\mathrm{ml} \min ^{-1} \mathrm{~g}^{-1}\right)$} \\
\hline Calmidazolium & $1.3 \pm 0.2$ & $1.1 \pm 0.1$ & $1.0 \pm 0.2$ \\
\hline Control & $1.2 \pm 0.1$ & $1.3 \pm 0.1$ & $1.3 \pm 0.1$ \\
\hline \multicolumn{4}{|c|}{$\mathrm{Na}$ reabsorption ( $\%$ of tubular load) } \\
\hline Calmidazolium & $86 \pm 4$ & $69 \pm 4$ & $57 \pm 4$ \\
\hline Control & $93 \pm 1$ & $76 \pm 4$ & $59 \pm 3$ \\
\hline \multicolumn{4}{|c|}{$Q \mathrm{O}_{2}\left(\mu \mathrm{mol} \mathrm{min} \operatorname{mog}^{-1} \mathrm{~g}^{-1}\right)$} \\
\hline Calmidazolium & $6.1 \pm 0.4$ & $3.8 \pm 0.3$ & $3.3 \pm 0.4$ \\
\hline Control & $6.2 \pm 1.1$ & $4.0 \pm 0.7$ & $3.9 \pm 0.9$ \\
\hline
\end{tabular}

${ }^{a}$ Functional parameters of isolated rat kidneys. At $45 \mathrm{~min}$ after the onset of perfusion, arterial $P_{2}$ was lowered from $500 \mathrm{mmHg}$ to $120 \mathrm{mmHg}$. Calmidazolium $(1 \mu \mathrm{M})$ was continuously added for a 45-min period starting $30 \mathrm{~min}$ after the onset of perfusion. Calmidazolium was omitted in controls. Values are means $\pm S E M$, $n=3$

duction when the $\mathrm{PO}_{2}$ was lowered from 500 to $120 \mathrm{mmHg}$, without altering other functional parameters (Fig. 3, Table 3), in particular the oxygen consumption rates. W-7 $(10 \mu \mathrm{M})$, a further putative calmodulin inhibitor, which structurally differs from calmidazolium [11], also prevented the rise of EPO formation at $\mathrm{PO}_{2}$ values of $120 \mathrm{mmHg}$ (EPO production rate: $0.24 \pm 0.07 \mathrm{U} \mathrm{h}^{-1}$ $\left.\mathrm{g}^{-1} ; n=4\right)$. When forskolin $(10 \mu \mathrm{M})$ and 8-bromocGMP $(100 \mu \mathrm{M})$ were applied at a $P \mathrm{O}_{2}$ of $120 \mathrm{mmHg}$, EPO formation rates remained unchanged $(1.1 \pm 0.1$ and $1.0 \pm 0.2 \mathrm{U} \mathrm{h}^{-1} \mathrm{~g}^{-1}$, respectively; $n=3$ for each condition). At the same time, forskolin $(10 \mu \mathrm{M})$ and 8 -bromocGMP $(100 \mu \mathrm{M})$ increased renal perfusate flow by $52 \pm 3 \%$ and $43 \pm 5 \%$ of control values without affecting other functional parameters, such as oxygen consumption.

\section{Discussion}

Our findings agree with and extend previous observations that the isolated perfused kidney releases erythropoietin (EPO) in an oxygen-dependent manner [7, 9, 16, 28]. Our data show that hypoxia-induced stimulation of EPO release is a phenomenon that is not just restricted to isolated perfused kidneys taken from hypoxic animals [7] but is also observed with kidneys taken from normoxic rats $[9,16,28]$. Since the normoxic rat kidney contains no stores for EPO [13] one can infer that the isolated perfused rat kidney is capable of de novo synthesis of EPO. EPO formation by the isolated perfused rat kidney moreover displays some characteristics that are also observed in vivo. First, it is inversely proportional to renal oxygen supply (Fig. 2, [17]). Secondly, the time lag of 60-90 min between decrease of oxygen supply and increase of EPO release (Fig. 1) is similar to the period after which serum 
EPO levels start to increase upon hypoxia in vivo [17]. And finally, the maximal rate of EPO production, which is estimated to be around $2 \mathrm{U} \mathrm{h}^{-1} \mathrm{~g} \mathrm{kidney}^{-1}$ in vivo [17], is comparable to the values calculated for the isolated perfused kidney. What differs in vivo is that the isolated perfused rat kidney stops producing EPO after $3 \mathrm{~h}$ of perfusion. We think that this phenomenon results from a functional exhaustion of the preparation, because other parameters, such as the sodium reabsorption rate and thereby the renal oxygen consumption, steadily decrease during the time of perfusion (Table 1). This functional deterioration is known to be a characteristic feature of kidneys perfused in vitro. Nevertheless, the continuous decrease of oxygen consumption, as particularly observed during perfusion at low $\mathrm{PO}_{2}$ values, was not ratelimiting for the hypoxia-induced elaboration of EPO by the isolated perfused rat kidney. Thus, our findings suggest that the essentials of the oxygen sensor controlling EPO formation are predominantly located in the kidney itself.

These data seem to be in contrast to the observation that selective reduction of oxygen supply to the kidneys by clamping of the renal arteries only causes a slight increase of the EPO formation rate, whereas lowering the systemic oxygen-transport capacity results in an exponential rise of serum EPO levels [20]. It should be remembered, however, that reduction of renal perfusion flow not only causes a reduction of renal oxygen delivery but also decreases the tubular sodium load and thereby locally alters renal oxygen consumption [4].

The signal transduction process that links EPO formation to the oxygen supply has not yet been elucidated, and it appears as if the isolated perfused rat kidney could be a suitable model to study this process. Recently, it was reported that adenosine causes a twofold stimulation of EPO release from the isolated perfused rat kidney [21]. Since intrarenal levels of adenosine increase during insufficient oxygen supply, it was suggested that adenosine could be a messenger molecule between oxygen supply and EPO production [8, 19, 22]. Cyclic AMP, cyclic GMP and calcium/calmodulin have also been suggested to have a role in this signal transduction process [8]. To test for a possible involvement of cyclic nucleotides in the signal transduction process, we used forskolin and 8-bromocGMP to increase cellular levels of cAMP and cGMP, respectively. Both drugs significantly decreased renal vascular resistance, but at the same concentrations neither forskolin nor 8-bromo-cGMP stimulated EPO production in kidneys perfused at $\mathrm{PO}_{2}$ values of $500 \mathrm{mmHg}$. Calmidazolium, a putative calmodulin antagonist [10], also had no stimulatory effect on EPO formation at high $\mathrm{PO}_{2}$ values.

It has been demonstrated that increasing cellular levels of cyclic AMP with forskolin had no effect on EPO formation in human hepatoblastoma (Hep G2) cells grown under normoxic conditions [27]. At the same time, however, forskolin further enhanced the stimulatory effect of hypoxia on EPO secretion from Hep G2 cells exposed to an atmosphere of $1 \%$ oxygen [27]. Therefore, in the present study, we have also examined the effects of forskolin and 8-bromo-cGMP on EPO production in iso- lated kidneys perfused under hypoxic conditions. Our finding that both drugs had no effect, in particular no additional stimulatory effect, on EPO production rates in isolated rat kidneys perfused at $P_{2}$ values of $120 \mathrm{mmHg}$ could indicate that the signal transduction mechanisms for EPO formation might not be principally the same in the human hepatoblastoma cell line Hep G2 as in the intact kidney.

Even more interesting might be our observation that the calmodulin antagonist calmidazolium blunted the increase of EPO formation when the oxygen pressure was lowered in the perfusate. This effect of calmidazolium was confirmed with W-7, another putative calmodulin inhibitor [11], which structurally differs from calmidazolium. Recently, evidence has been provided for a link between the regulation of EPO production and proximal-tubular energy consumption [6]. It might be conceivable, therefore, that calmodulin antagonists exert their effects by lowering the activity of the proximal tubular work. However, as compared to controls, calmidazolium and W-7 had no obvious side-effects on renal functional parameters, particularly not on sodium reabsorption and oxygen consumption. Moreover, since all of these drugs were constantly infused into the kidneys and at the same time continuously removed from the circulation by dialysis, it appears rather unlikely that the inhibitory action of calmidazolium and W-7 on hypoxia-induced EPO formation was a toxic effect due to accumulation of the compounds. It seems possible, therefore, that a calmodulinactivated reaction is somehow involved in the oxygen-dependent EPO production. From the observation that calmidazolium and W-7 both blunted the increase of EPO formation induced by oxygen depletion whereas basal EPO production (at a $\mathrm{PO}_{2}$ of $500 \mathrm{mmHg}$ ) remained nearly unaffected, one might infer that these drugs affect the oxygen-sensing mechanism rather than the synthesis and processing of EPO. The identification of this reaction step remains a task for future research.

Acknowledgements. The authors wish to thank W. Gehret and U. Vogel for their expert technical assistance. This study was supported by a grant of the Swiss National Science Foundation (no. 3.165.88). H.-J. Sch. is a recipient of a fellowship of the Hoffmann-La Roche foundation. K.-U. E. acknowledges a fellowship from the Deutsche Forschungsgemeinschaft.

\section{References}

1. Bauer C, Kurtz A (1989) Oxygen sensing in the kidney and its relation to erythropoietin production. Annu Rev Physiol 51:845-856

2. Beru N, Mc Donald J, Lacombe C, Goldwasser E (1986) Expression of the erythropoietin gene. Mol Cell Biol 6:2571-2575

3. Bondurant MC, Koury MJ (1986) Anemia induces accumulation of erythropoietin mRNA in the kidney and liver. Mol Cell Biol 6:2731-2733

4. Deetjen $\mathrm{P}$, Kramer $\mathrm{K}$ (1961) Die Abhängigkeit des $\mathrm{O}_{2}$-Verbrauchs der Niere von der Na-Rückresorption. Pflügers Arch 273:636-650

5. Eckardt KU, Kurtz A, Hirth P, Scigalla P, Wieczorek L, Bauer C (1988) Evaluation of the stability of human erythropoietin in samples for radioimmunoassay. Klin Wochenschr 66:241-245

6. Eckardt KU, Kurtz A, Bauer C (1989) Regulation of erythropoietin production is related to proximal tubular function. Am J Physiol 256:F942-F947

7. Erslev AJ (1974) In vitro production of erythropoietin by kidneys perfused with a serum-free solution. Blood 44:77-85 
8. Fisher JW (1988) Pharmacologic modulation of erythropoietin production. Annu Rey Pharmacol Toxicol 28:101-122

9. Fisher JW, Birdwell BJ (1961) The production of an erythropoietic factor by the in situ perfused kidney. Acta Haematol 26:224-232

10. Gietzen K, Sadorf I, Bader H (1982) A model for the regulation of the calmodulin-dependent enzymes erythrocyte $\mathrm{Ca}^{2+}$-transport ATPase and the brain phosphodiesterase by activators and inhibitors. Biochem J 207:541-548

11. Itoh $H$, Hikada $H$ (1984) Direct interaction of calmodulin antagonists with calcium/calmodulin-dependent cyclic nucleotide phosphodiesterase. J Biochem (Tokyo) 96:1721-1726

12. Jacobson LO, Goldwasser E, Fried W, Plzak L (1957) Role of the kidney in erythropoiesis. Nature 179:633-634

13. Jelkmann W (1982) Temporal pattern of erythropoietin titers in kidney tissue during hypoxic hypoxia. Pflügers Arch 393:88-91

14. Jelkmann W (1986) Renal erythropoietin: properties and production. Rev Physiol Biochem Pharmacol 104:140-215

15. Koury ST, Bondurant MC, Koury MJ (1988) Localization of erythropoietin synthesizing cells in murine kidneys by in situ hybridization. Blood 71:524-527

16. Kuratowska Z, Lewartowski B, Michalak E (1961) Studies on the production of erythropoietin by isolated perfused organs. Blood $18: 527-534$

17. Kurtz A, Eckardt KU, Tannahill L, Bauer C (1988) Regulation of erythropoietin production. Contrib Nephrol 66:1-16

18. Lacombe C, da Silva JL, Bruneval P, Fournier JG, Wendling F, Casadevall N, Camilleri JP, Bariety J, Varet B, Tambourin P (1988) Peritubular cells are the site of erythropoietin synthesis in the murine hypoxic kidney. J Clin Invest 81:620-623
19. Osswald $H$ (1983) Adenosine and renal function. In: Berne RM, Roll TW, Rubio R (eds) Regulatory function of adenosine. Nijhof, London, pp 399-415

20. Pagel H, Jelkmann W, Weiss C (1988) A comparison of the effects of renal artery constriction and anemia on the production of erythropoietin. Pflügers Arch 413:62-66

21. Paul P, Rothmann SA, Meagher RC (1988) Modulation of erythropoietin production by adenosine. J Lab Clin Med 112:168-173

22. Ramos-Salazar A, Baines AD (1986) Role of $5^{\prime}$-nucleotidase in adenosine-mediated renal vasoconstriction during hypoxia. J Pharmacol Exp Ther 236:494-499

23. Schmidt FH (1961) Die enzymatische Bestimmung von Glucose und Fruktose nebeneinander. Klin Wochenschr 39:1244-1247

24. Schurek HJ, Alt JM (1981) Effect of albumin on the function of perfused rat kidney. Am J Physiol 240:F569-F576

25. Schuster SJ, Wilson JH, Erslev AJ, Caro J (1987) Physiologic regulation and tissue localization of renal erythropoietin messenger RNA. Blood 70:316-318

26. Schuster SJ, Badiavas EV, Costa-Giomi P, Weinmann R, Erslev AJ, Caro J (1989) Stimulation of erythropoietin gene transcription during hypoxia and cobalt exposure. Blood 73:13-16

27. Ueno M, Seferynska I, Beckmann B, Brookins J, Nakashima J, Fisher JW (1989) Enhanced erythropoietin secretion in hepatoblastoma cells in response to hypoxia. Am J Physiol 257:C743-C749

28. Zangheri EO, Campana H, Ponce F, Silva JC, Fernandez FO, Suarez JRE (1963) Production of erythropoietin by anoxic perfusion of the isolated kidney of a dog. Nature 199:572-573 